\title{
Experimental and Analytical Study of the Cold Flow Inside a Ramjet Test Engine
}

\author{
Leonardo César Freitas ${ }^{1, *}$ (D), Olexiy Shynkarenko ${ }^{1}$ (D) \\ 1.Universidade de Brasília - Faculdade do Gama - Departamento de Engenharia Aeroespacial- Brasília/DF - Brazil. \\ *Correspondence author: Icf.250396@gmail.com
}

\section{ABSTRACT}

The work is focused on the performance estimation and control of a cold flow inside a ramjet test engine, which initially operates without combustion, preparing the flow for the main propulsive phase. To achieve this objective, a "connected pipe" test bench was assembled. Flow management was performed using the control valve that allows regulating pressure and air mass flow rate in the engine according to its flight conditions through sensors installed at relevant positions. The proportional, integral and derivative (PID) parameters for the flow control algorithm were studied in order to guarantee the stable operation of the engine and correspondence of the flow parameters to predicted ones by the analytical modeling. Experimental results were validated by the numerical and analytical compressible flow models.

Keywords: Ramjet engines; Test facilities; Optimal control; Cold flow tests; Compressible flow.

\section{INTRODUCTION}

A ramjet is an airbreathing engine that is characterized by having no compressor and turbine sections, unlike a turbofan engine, used in commercial aircrafts. Flow compression is performed by means of a supersonic diffuser that transforms the kinetic energy of the flow into potential energy, increasing its pressure and temperature. After this process, fuel is mixed with air in the combustion chamber, and this mixture, which constitutes the propellant, is burned (Sutton and Biblarz 2010; Hill and Peterson 1992). Flame holders of various configurations are generally used for the flame stabilization inside the combustion chamber due to high flow-to-flame relative velocity. Finally, the combustion products are accelerated and expanded into the atmosphere.

The ramjet engine is generally used in missiles, but its simplicity increase goes along with a limitation: it cannot produce static thrust and cannot operate from rest (Hill and Peterson 1992). As a consequence, ramjet missiles are often equipped with a booster stage that accelerates a missile to supersonic speed at which the ramjet works efficiently (Fry 2004), it does not have to store onboard oxidizer which would increase its weight, but rather aspirate it. Sarisin (2005) further states that the ramjet has a higher specific impulse than a rocket engine and potential for greater range. However, its operating altitude is limited as it depends on the air intake.

Like any type of engine, a ramjet must be tested before going into operation. Usually, the first type of test to be done on this engine is the "connected pipe" (CP) test, which aims to evaluate the combustion chamber's structural integrity and efficiency using components that simulate the pressure and temperature conditions to which the engine will be subjected in flight (Sarisin 2005). Studies that are usually done after CP tests are the "semi-free jet test", in which the whole engine is tested and the "free jet test", in

Received: Feb. 10, 2020 | Accepted: Oct. 10, 2020

Peer Review History: This is a peer reviewed version of selected paper presented at the $2^{\circ}$ Congresso Aeroespacial Brasileiro occurred in 16 -19 September of 2019 at Universidade Federal de Santa Maria, Santa Maria/RS, Brazil.

Section Editor: Marcelo Serrano Zanetti 
which the ramjet-propelled vehicle is tested (Sarisin 2005). The last two studies are more complex and more expensive than the CP test (Sarisin et al. 2006). In addition, the CP test requires a lower mass flow rate than the others (Esirgen 2014).

The main object of the current study is the ramjet test engine. It was developed and built by the Chemical Propulsion Laboratory (CPL) of the University of Brasilia in terms of the research project Design and development of a high-maneuverability supersonic missile with ramjet engine. The experimental testing of this engine includes several stages, one of them is the development of a control program of the air valve in order to achieve various operation modes: i) initial flow control for engine ignition, ii) main flow control during the propulsive phase, iii) flow termination (CPL, 2017). The flow behavior in this system is highly nonlinear due to the compressibility, turbulence, and combustion processes, thus it requires a deep study of control and predictable system operation. Due to these considerations, a $\mathrm{CP}$ test bench has been built for experimental testing.

Thus, the main objective of this work is the experimental analysis of the cold flow (without combustion) in the CPL test bench and construction of an analytical flow model in the engine.

\section{METHODOLOGY}

To achieve the main objective of the work, a ramjet engine test bench has been set up, a proportional, integral and derivative (PID) control system has been implemented and a cold flow model based on the isentropic compressible flow equations, according to Anderson (2016), has been constructed.

\section{Experimental Setup}

\section{Test bench schematics and assembly}

The air duct of the test bench shown in Fig. 1 consists of the following components: i) compressed air tank, ii) piping, manual valve, iii) flow control valve, iv) ignition system, v) heater, vi) combustion chamber with a supersonic nozzle.

The system components are assembled using standard ASME B16.5 for flange connections. The system is designed to operate using liquid (propane) or solid fuel (paraffin and polyethylene) for ramjet engines. However, in the current work, cold tests only have been performed and the fuel supply system was not introduced.

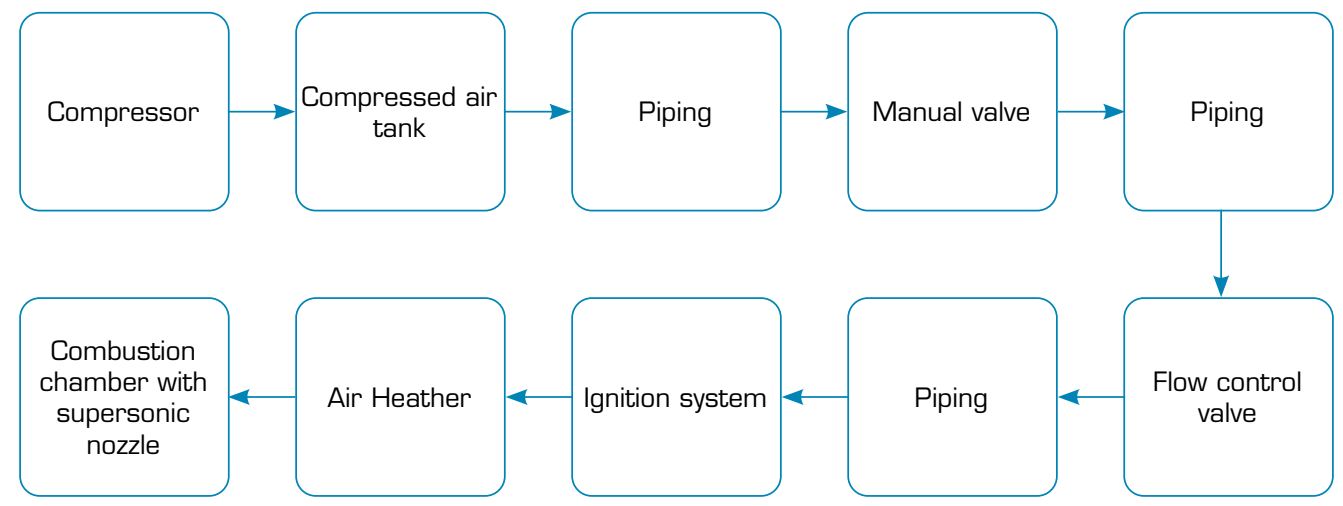

Figure 1. Schematic of the connected pipe test bench.

The compressor supplies the air tank with $5 \mathrm{~m}^{3}$ by a pressure of 10 bar. Such volume of the tank allows executing the flow tests up to $40 \mathrm{~s}$. According to Esirgen (2014), a tank capacity should be high for long tests, and the final tank pressure should be higher than a ramjet combustion chamber pressure in order to compensate losses in the flow path. The maximum allowable tank pressure is 16 bar, which could be achieved by injecting additional air-oxygen mixture from the high-pressure tanks for the oxidizer utilization in the air heater. Pressure and temperature sensors have been installed inside the tank for the stagnation 
properties measurement during the test. The condensed water has been drained through solenoid valves installed in the air tank and compressor.

The following parts have been installed between the air storage tank and the manual ball valve: i) a "knee", which directs the flow downwards, ii) a straight upright tube, iii) a second knee, which directs the airflow in a horizontal direction, iv) a straight horizontal tube. An S-shaped tube has been installed between the manual valve and the control valve in the horizontal plane. A pressure sensor has been installed near the end of this tube to measure the pressure prior to the control valve. A straight horizontal pipe with a pressure sensor was installed after the control valve. A flexible pipe connects the air supply system with the engine to mitigate the propagation of vibrations from the engine rear to the air supply system (Inman 2014).

Stainless steel AISI 304L was used for the air pipes (cold flow ducts) and AISI 310S for hot flow ducts: the combustion chamber, fuel injection system, ignition system, nozzle support, etc. Such materials have high corrosion resistance due to their capability to form the chromium oxide $\left(\mathrm{Cr}_{2} \mathrm{O}_{3}\right)$ protective layer on the surface of pipes (Mouritz 2012).

\section{Flow Control Valve}

The airflow control valve aims to regulate the flow properties on the inlet of the ramjet engine (a diffuser), reducing the pressure according to the test program (Sarisin 2005). The valve assembly used in this project consists of three main components: a mechanical globe valve, an electropneumatic linear positioner, which receives an analog electrical signal and converts it into pressure variation, and a spring-diaphragm-type pneumatic actuator, which receives pressurized air of 2.5 bar from the positioner and converts it in motion to a stem responsible for the degree of opening of the valve. The actuator can assume various discrete positions between "fully closed" and "fully open" (EAS 2017, p. 24). According to the valve specifications, its maximum mass flow rate is $2 \mathrm{~kg} / \mathrm{s}$. Because of its large size, the mechanical and pneumatic characteristic times of the valve are quite large, the complete valve opening or closing lasts from 4 to $7 \mathrm{~s}$. A big valve response time adds an additional complexity to the building of an efficient algorithm of the valve control program.

\section{Sensors}

Two types of sensors have been used in this project and installed at different positions on the test bench (Table 1). Pressure sensors Danfoss MBS-1700 were used for the estimation and control of the flow pressure in the feeding lines and inside the tank. The pressure was acquired with $200 \mathrm{~Hz}$ frequency. The active pressure sensor requires 9-32 V DC supply voltage, providing 4-20 mA output with a response time that is less than $4 \mathrm{~ms}$ (Danfoss 2016).

Table 1. Sensors installed for the cold flow tests.

\begin{tabular}{ccc}
\hline ID & Sensor type & Position \\
\hline P1 & & Tank \\
P2 & Pressure: Danfoss BS-1700 control valve \\
P3 & After control valve \\
P4 & Air heater \\
P5 & Combustion chamber \\
T1 & Tank \\
T2 & Bemperature: Omega KQXL-18U-12, \\
T3 & KQXL-18U-6 & After air heater \\
T4 & & Nozzle \\
\hline
\end{tabular}

The thermocouples used in the project are Omega KQXL-18U-12 and KQXL-18U-6. They are working on the Seebeck Effect producing a voltage between the ends of a heat conductor due to the temperature differential. The typical response time for such 
thermocouple is close to $0.55 \mathrm{~s}$ (Omega Engineering 2019). Not all sensors presented in Table 1 were used in the current study nor have direct relation to this work. They are going to be explored in further publications and are kept to show consistency with future studies.

\section{Fuel Line and Igniter}

The cold flow tests were performed in the current work, therefore the fuel line and the ignition system (Shynkarenko et al. 2019b) had been sealed and are not in operation. Fuel inlet lines and the igniter interfaces were closed with caps to prevent the backflow and leakage of the air. The assembly of the air duct containing igniter and fuel supply lines is shown in Fig. 2.

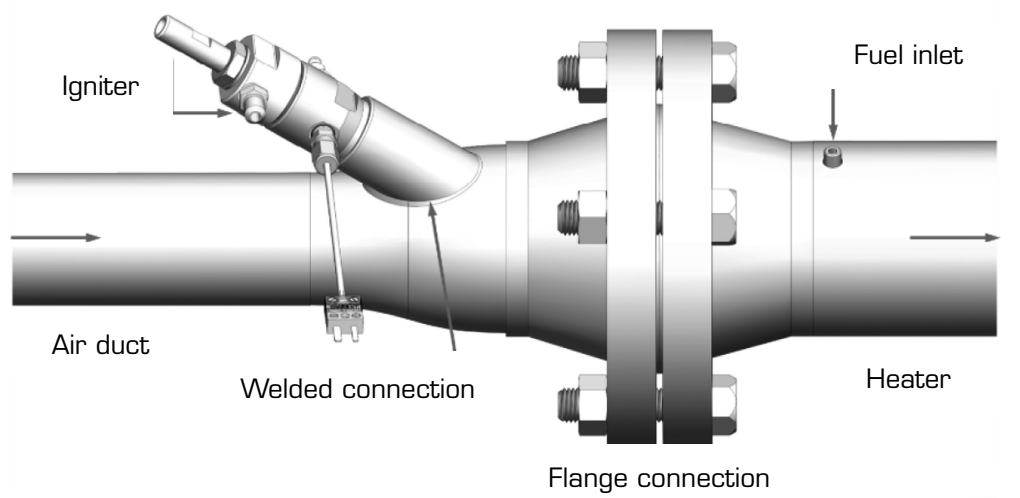

Figure 2. Subassembly of the test stand: air duct, heater, and igniter.

\section{Flow Heater}

The airflow heater aims to create the vitiated flow conditions (pressure, mass flow rate, and temperature) equivalent to flow properties at the diffuser exit of a flying ramjet. Its main purpose is to increase the air temperature using the combustion of a relatively small fuel quantity with additional oxygen, thus the global oxygen balance in the mixture would not change (Esirgen 2014). However, according to Sarisin (2005), this heating method could slightly change the molecular weight of the mixture. The flow temperature would be controlled by the previously developed algorithm similar to Shynkarenko et al. (2019a). The combustion heater used in the current work has the following advantages: low fuel consumption, simple operation, and low maintenance costs.

As in this work, the fuel line was not assembled, its function is only to continue the airflow, as the other pipes, taking into account local pressure losses when the flow passes through the expansion and compression regions, cavities, and other obstacles like sensors, fuel collector, injectors, flame holder, etc.

\section{Combustion Chamber}

A cold flow passes around the ramjet combustion chamber elements: the fuel injectors and flame stabilization system towards the nozzle, losing some part of its total energy. The average flow velocity inside the combustion chamber should be low $(M<0.05)$ to organize efficiently the combustion process, so the pressure losses here are small.

The pressure in the combustor should be high enough for the fluid to reach supersonic velocity at the nozzle outlet (Anderson 2016). The operating pressure of the test engine for hot flow tests is 4 bar and for cold flow tests is 2 bar.

\section{Supersonic Nozzle}

A supersonic nozzle aims to accelerate the fluid that passes through it continuously. It consists of two parts: the convergent part, where the flow is subsonic, and the divergent part, where the flow is supersonic, as illustrated in Fig. 3. 


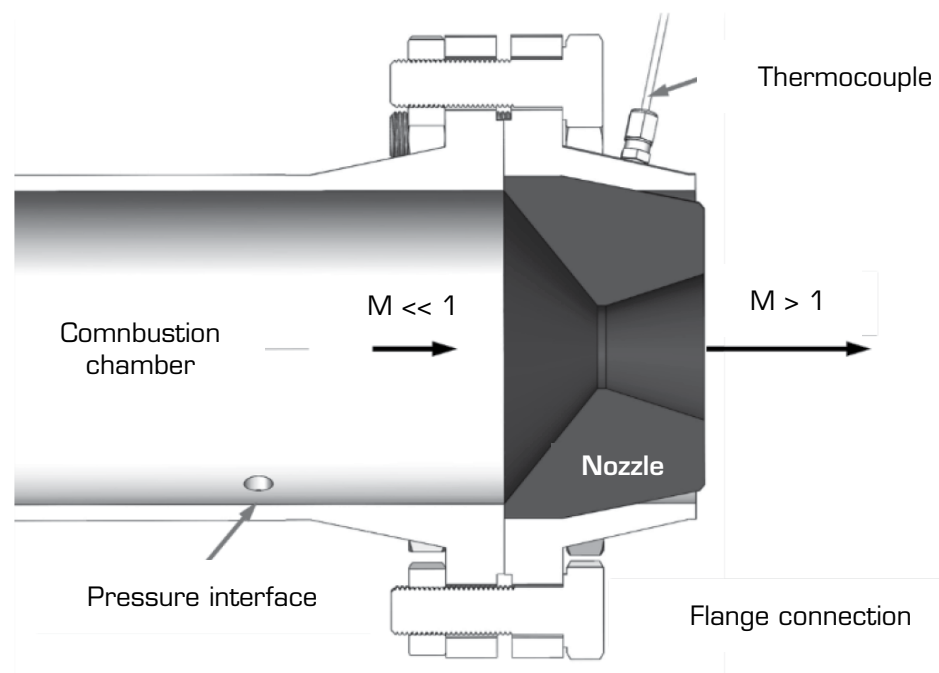

Figure 3. Nozzle subassembly.

Considering that the Mach number $M=V / a$, where $V$ is the flow velocity and $a$ is the speed of sound, the variation of Mach number along the nozzle can be described by the area-Mach number relation shown in Eq. 1 (Anderson 2016).

$$
\left(\frac{A}{A^{*}}\right)=\frac{1}{M^{2}}\left[\frac{2}{\gamma+1}\left(1+\frac{\gamma-1}{2} M^{2}\right)\right]^{\frac{\gamma+1}{\gamma-1}}
$$

where $A$ is any cross-sectional area of the nozzle, $A^{*}$ is the minimum flow area (throat) and $Y=1.4$ is the air specific heat ratio for the ideal gas. Equation 1 provides two solutions of $M$ for each value of $A$, one subsonic $(M<1)$ and one supersonic $(M>1)$.

The graphite nozzle has been used in the current project, material that is characterized by having good thermal shock resistance (Souza 2014) and the melting point between 4000 and $5000 \mathrm{~K}$ (Savvatimskiy 2005).

\section{Data Acquisition System}

The Data Acquisition System (DAQ) based on the National Instruments CompactDAQ solution has been used in the current research project in order to control the flow system through the electronic devices installed in the engine (control valve positioner and sensors). It is composed by the following modules:

- Chassis NI 9178 has been used as a base module, allowing to send and receive signals from a computer with control software. It also allows to start, pause or stop the data acquisition and to start or pause output signal generation (NI 2016a);

- Current output module NI 9265 has been used to perform generation of the valve control signal of 0-20.6 mA with frequency up to $100 \mathrm{kHz}$ (NI 2015);

- Thermocouple input module NI 9213 has been used to obtain the temperature data in the range of $\pm 78.125 \mathrm{mV}$ from 16 independent channels, up to $75 \mathrm{~S} / \mathrm{s}$ (samples per second) per channel (NI 2017);

- Current input module NI 9208 has been used to obtain pressure sensor data, up to $500 \mathrm{~S} / \mathrm{s}$ per channel from 16 channels. Its input signal amplitude is $\pm 22 \mathrm{~mA}$, it should be further converted to pressure units using a transformation function (NI 2016b).

\section{Analytical Flow Model}

The analytical model of the flow inside the ramjet test engine was calculated from a simplified schematic presented in Fig. 4. The flow process was considered isentropic in all air duct except the choked flow region on the valve 2. The air expansion in the 
tank is assumed adiabatic because the engine characteristic operation time is smaller than the characteristic heat transfer time between the gas and the tank wall.

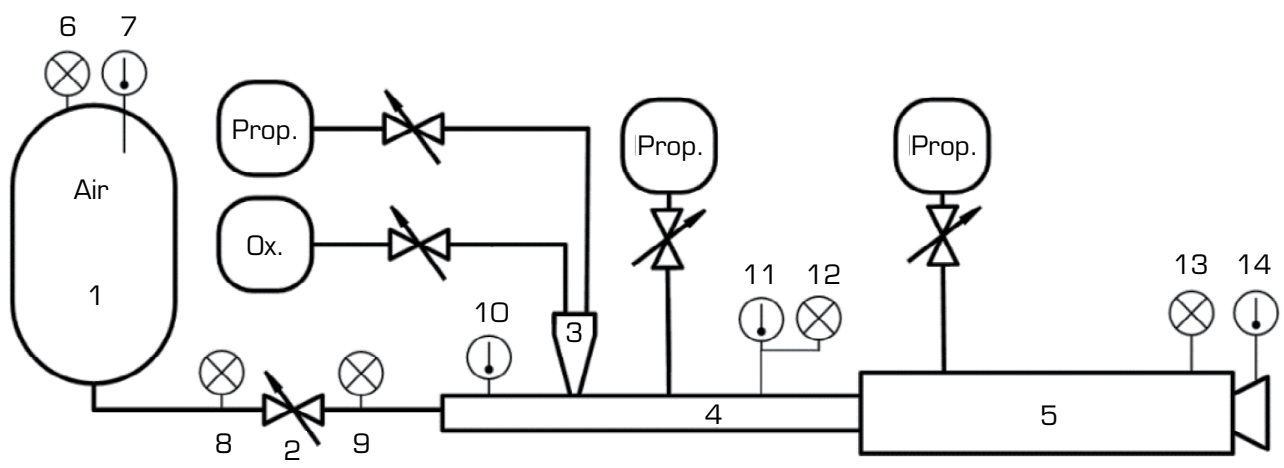

Figure 4. Flow system schematic. 1 - compressed air tank, 2 - flow control valve, 3 - igniter, 4 - airflow heater, 5 - combustion chamber, 6, 8, 9, 12, 13 - pressure sensors, $7,10,11,14$ - temperature sensors, Prop. - propellant, Ox. - oxidizer (GOX).

Thus, the thermodynamic properties of the flow inside the tank at any time moment could be calculated as described by Eqs. 2 and 3 (Anderson 2003):

$$
\begin{aligned}
& \frac{p_{i}}{p_{1}}=\left(\frac{T_{i}}{T_{1}}\right)^{\frac{\gamma}{\gamma-1}} \\
& p_{i} V=m_{i} R T_{i}
\end{aligned}
$$

where $P_{i}$ - static pressure at $i$-th time moment in the air tank; $P_{i}$ - initial tank pressure at a time $t=0$; $V$ - volume of the air tank; $m_{i}$ - mass of air inside the tank; $R$ - specific gas constant, $T_{i}$ - static temperature in the tank.

Local supercritical regime is performed in the section of the control valve 2 (Fig. 4 ) when the gas velocity becomes supersonic due to the pressure drop on the valve. The choked flow regime allows to organize aerodynamic and acoustic splitting of the flows between the tank and the engine in such a way that flow perturbations from the engine would not propagate backward in the flow. A normal shock wave equation system has been used in this region, according to Anderson (2016).

The flow in the heater, combustion chamber and nozzle was considered isentropic, following the area-Mach number relation (Eq. 1). The supersonic flow in the nozzle exit allows simulating the flight conditions on the test bench because in such cases the ambient conditions would not influence on the chamber pressure.

Real-time calculation of the air mass flow rate is based on recorded values of $P_{i}$ and $T_{i}$ during the test. The mass flow rate has been numerically calculated; it is based on the experimental mass estimation at every time instance using the following first-order approximation (Eq. 4):

$$
\dot{m}_{i}=\frac{m_{i}-m_{i-1}}{t_{i}-t_{i-1}}
$$

where $\dot{m}_{i}$ - mass flow rate, $t_{i}-t_{i-1}=$ const - time step.

Due to high thermal inertia in the tank, the airflow temperature measurement would always present a delay caused by a small thermal gradient between expanding gases and the sensor. So, the temperature measurements would be acceptable 
only for total conditions, when the temperature is stabilized for a long time, and could also be calculated during the flow process according to Eq. 3 .

\section{PID Control Implementation}

The control valve and pressure sensors connected to the DAQ form a closed electropneumomechanical system with feedback where pressure after the valve (Fig. 4, it. 9) has been chosen as a goal function. It could be efficiently controlled with the implementation of PID algorithms. The valve opening level has been used as an independent parameter for the mathematical interpretation of a goal pressure function. PID control is generally described as Eq. 5 (Ogata 2010):

$$
c(t)=K_{p} e(t)+\frac{K_{p}}{T_{i}} \int_{0}^{t} e(t) d t+K_{p} T_{d} \frac{d e(t)}{d t}
$$

Where $K_{p}$ - proportional gain, $T_{i}$ - integral time, $T_{d}$ - derivative time, $e(t)$ - "error signal" (the difference between current and desired pressure values), $c(t)$ - controlled value.

The input signal could be presented as a step function. The response to this type of function should ideally behave according to Fig. 5 (Ogata 2010).

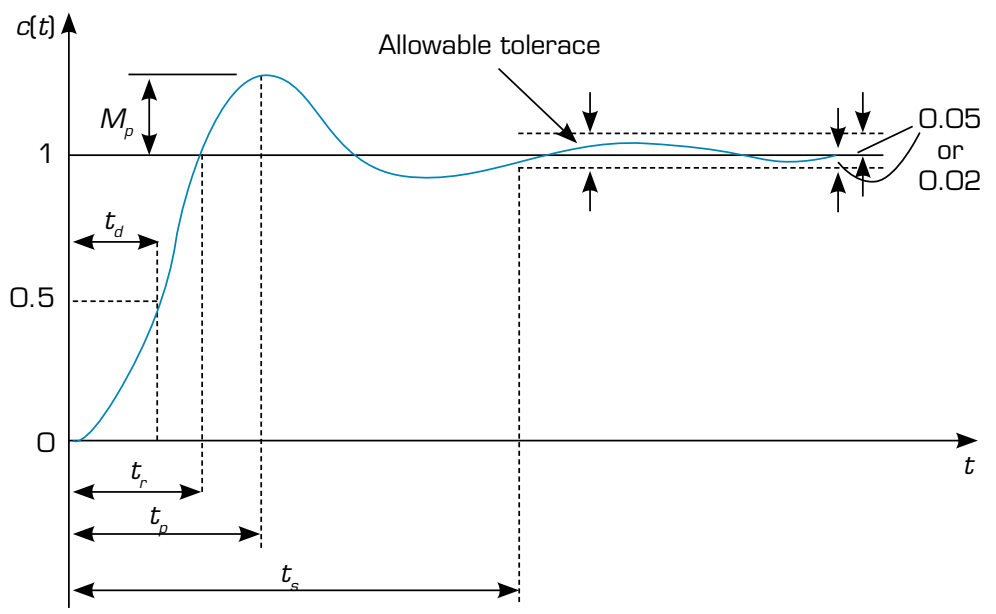

Figure 5. Step function response.

Some characteristics of the output (Fig. 5) could be described as follows:

- Delay time $\left(t_{d}\right)$ of the response to reach $50 \%$ of the final value;

- Rise time $\left(t_{r}\right)$ of the response to go from 0 to $100 \%$ of the desired value;

- Peak time $\left(t_{p}\right)$ to reach the first peak;

- Maximum overshoot $\left(M_{p}\right)$ of the output as a percentage of the final value;

- Settling time $\left(t_{s}\right)$ of the process variable to enter and remain within a maximum allowable value range of 5 or $2 \%$ of input error. A preliminary search of adequate PID characteristics is made using the theoretical methods (Frank 2018). The methods of Ziegler-Nichols and Chien-Hrones-Reswick have been used for the preliminary estimation of the control coefficient values.

\section{Preparation of the Cold Flow Tests}

The goal relative pressure of 2 bar on diffuser exit (Fig. 4) was selected for the tests, it corresponds to $17.5 \mathrm{~km}$ of flight altitude and $M=3$ for a typical ramjet engine, according to Shynkarenko et al. (2019a). Test duration of $20 \mathrm{~s}$ has been chosen and the sampling interval $t_{i}-t_{i-1}=5 \mathrm{~ms}$. In total 4,000 samples have been acquired in each experiment. The air tank initially was pressurized up to 10 bar. 


\section{RESULTS AND DISCUSSION}

The most relevant data obtained from the cold flow test are illustrated in Figs. 6 to 10. Some data oscillations could be observed on these graphs (noise) due to interference of an electric nature, to which the sensors are subjected, and transient flow processes captured by pressure and temperature sensors. Reduction of the noise has been made applying the filtering process, eliminating high or low frequencies in electric signals (MC 2012) by the DAQ modules. The maximum pressure error estimated taking into account the sensor characteristics, signal transfer, amplification and transformation function is close to $\pm 1.0 \%$ (Araujo 2019 ).

It is important to emphasize that the pressure sensor measurements are providing more data for the analysis than the thermocouple, due to its slower response time. In addition, the sampling rate of the thermocouple DAQ module NI 9213 is 75 S/s, it has been interpolated to global data acquisition frequency of $200 \mathrm{~S} / \mathrm{s}$ by the internal DAQ algorithm. Thus, changes of the flow temperature vary slowly with respect to pressure (Anderson 2016), such a situation does not pose a problem for the analysis of test data.

Figure 6 illustrates the variation of the stagnation pressure in the tank and static pressure 8 (Fig. 4) in the line as a function of time. The pressure decays as predicted by Eq. 4 . The initial tank pressure was near 9.36 bar and the final pressure was close to 7.39 bar. Thus, the pressure drop in the tank during the test was 1.97 bar.

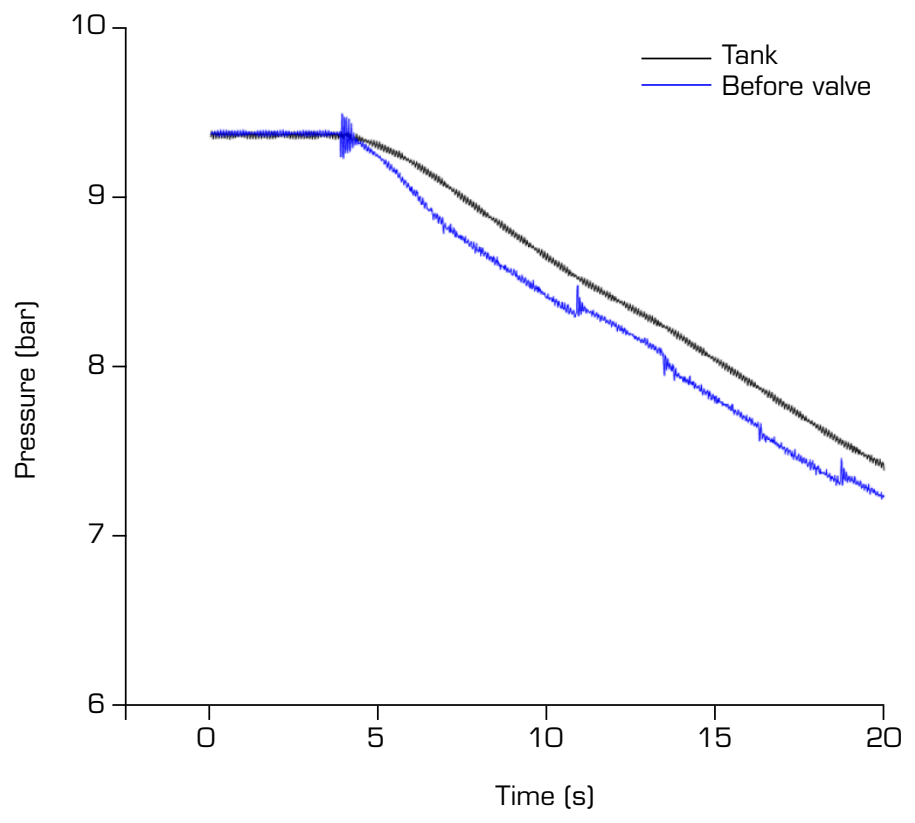

Figure 6. Tank and line pressures in terms of test time.

The pressure before the valve is similar to the tank pressure (Fig. 6). Some small pressure differences could be observed due to the flow movement, compressibility effects $(M \approx 0.1)$ and local pressure losses (sudden flow constraint, 4 elbows of $90^{\circ}$ and long straight pipes). The pressure drop also depends on the valve opening level, as could be seen in Fig. 6 from 10 to $11 \mathrm{~s}$; more constrained flow results in lower flow velocity and smaller pressure difference. An average pressure drop was found to be around $1.9 \%$. The total pressure drop from the tank to valve characterizes a non-isentropic flow (Anderson 2016) due to bends and inlets (White 2011).

Figure 7 represents the static pressure behavior in the pipe after the valve, controlled by the PID algorithm for two cases: initial and optimized PID values. The initial PID values were found experimentally after a number of tests using the "trial and error" method. Initially predicted by the Ziegler-Nichols method, PID constants were studied on series of experiments. A similarity of the pressure plot with the theoretical curve (Fig. 5) can be noticed. Here, the delay time is $5.04 \mathrm{~s}$, the rise time is $6.25 \mathrm{~s}$, the peak time is $7.45 \mathrm{~s}$, the maximum overshoot is $126 \%$, the final error is $10.49 \%$ of the goal pressure. The analysis shows that the system response did not stabilize as the final error was higher than $5 \%$. 


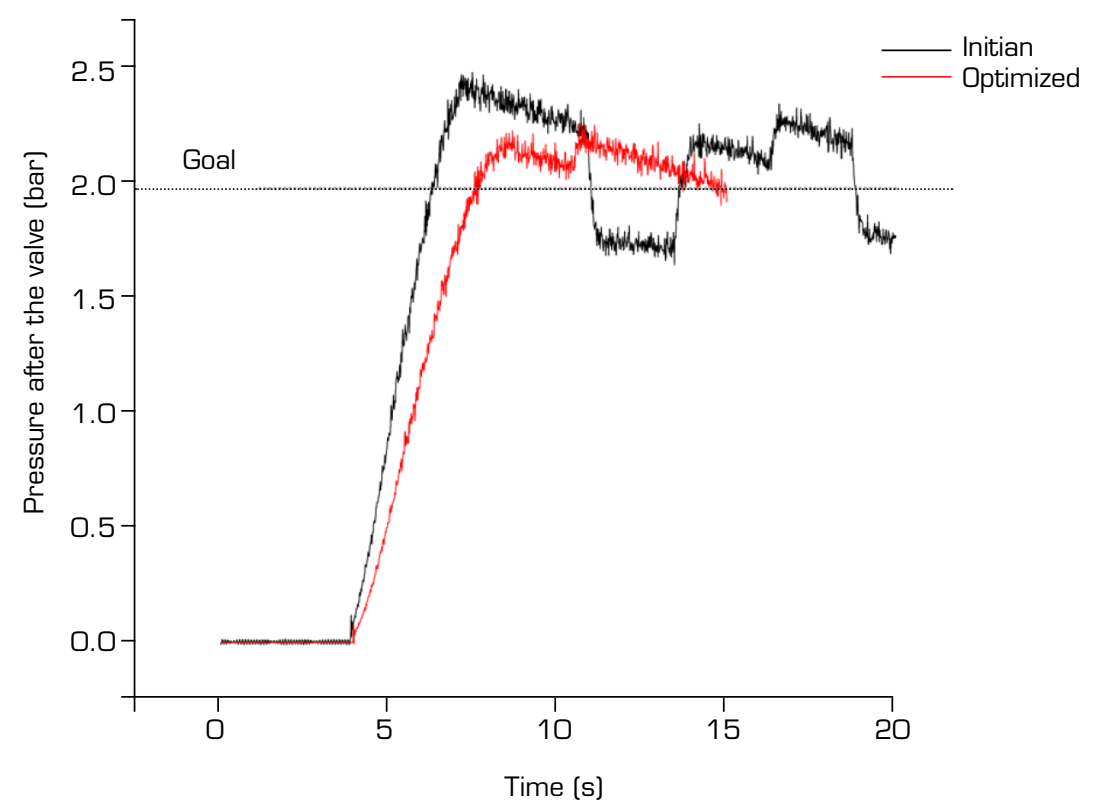

Figure 7. Pressure after the valve (bar) as a function of test time (s).

After experimental identification of PID limits, a large number (hundreds) of experiments have been executed and optimized control constants were found, one of the final results is presented in Fig. 7. It is characterized by $50 \%$ reduced overshoot values with respect to the initial pressure variation. Taking into consideration the scale of the test bench and complexity of the experimental setup, optimization of the cold flow control took approximately one year of the experimental work.

The average pressure drop received on the control valve was $6.87 \mathrm{bar}$, which is consistent with the statement that a commercial valve provides a pressure drop ranging from 5 to 25 bar (Sarisin 2005).

The average pressure drop between the tube after the valve and the heater was 0.018 bar; between the heater and the combustion chamber, an average static pressure increase of 0.008 bar was observed due to the growth of the engine cross-sectional area and flow deceleration.

Figure 8 shows the temperature variation in the tank measured experimentally and estimated numerically by Eq. 3 . The measured initial temperature was $24^{\circ} \mathrm{C}$ and the final temperature was $21^{\circ} \mathrm{C}$, where the calculated final temperature was $4{ }^{\circ} \mathrm{C}$.

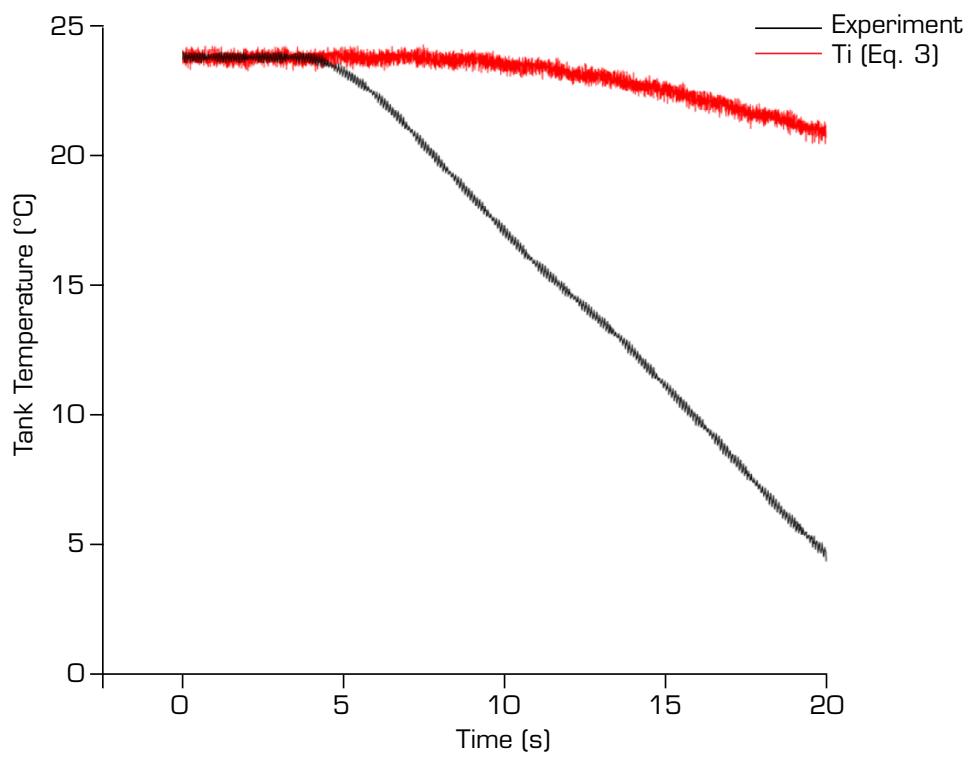

Figure 8. Tank temperature $\left({ }^{\circ} \mathrm{C}\right)$ as a function of test time $(\mathrm{s})$. 
Figure 9 shows the air mass flow rate calculated by Eq. 4 based on experimental measurements of pressure in the tank. As a result of processing of the pure experimental data, the noise in the output result (Fig. 9) could be observed. The trendline has been built over the pure result allowing to filter the oscillations and to present the mass flow rate function in a more continuous way. The average mass flow rate of air was $0.55 \mathrm{~kg} / \mathrm{s}$, a total air mass consumption during the test was $8.55 \mathrm{~kg}$. Considering that the initial air mass is $55.02 \mathrm{~kg}$, the relative air consumption was around $15.5 \%$.

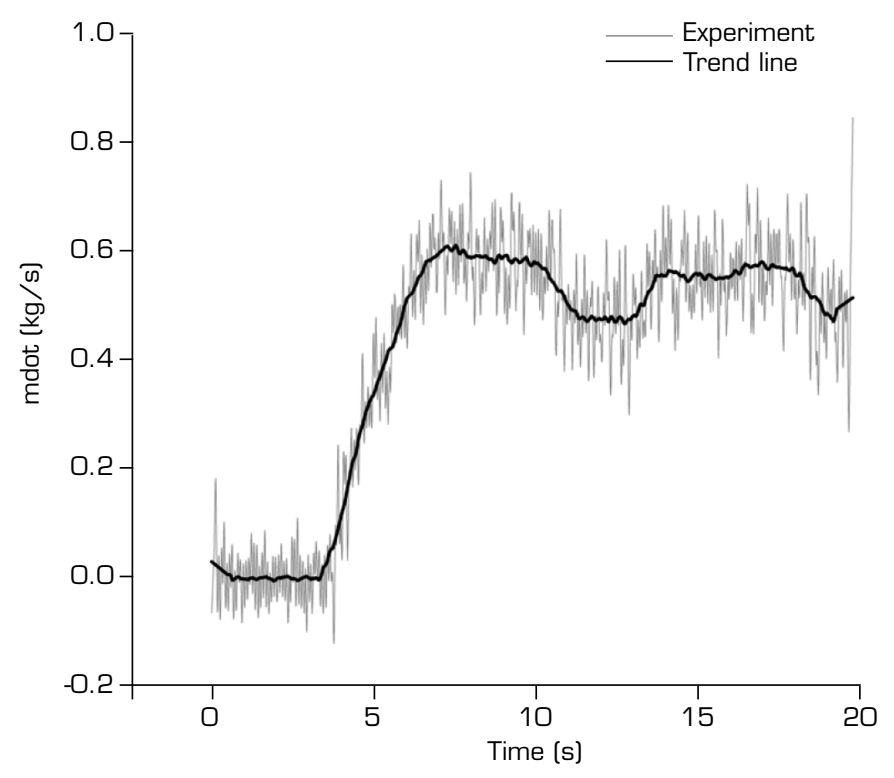

Figure 9. Mass flow rate $(\mathrm{kg} / \mathrm{s})$ as a function of test time (s).

Figure 10 shows the variation of the control current applied to the valve positioner during the test for the initial and optimal flow cases. Its initial value of $6 \mathrm{~mA}$ corresponds to the fully closed position and $20 \mathrm{~mA}$ to fully open position. This plot demonstrates sensitivity of optimal flow control to the input signal, where precise signal output directly influences on the quality of the flow regulation.

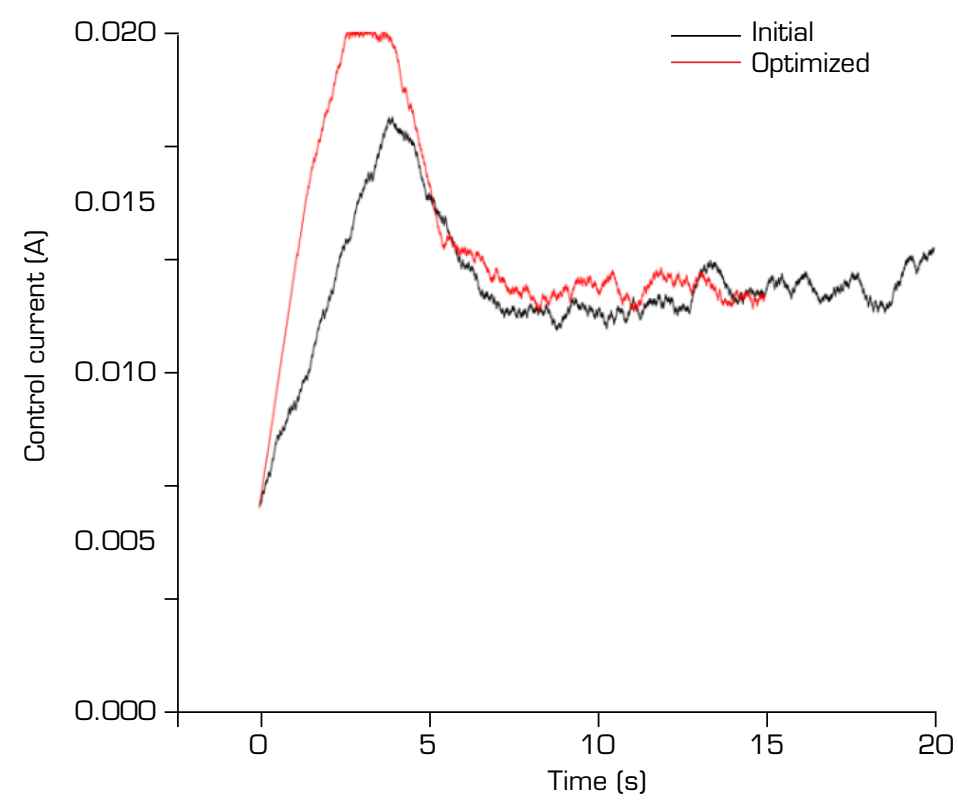

Figure 10. Valve control input (A) as a function of test time (s). 


\section{CONCLUSIONS}

Theoretical and experimental studies of cold airflow control inside a ramjet engine made possible to estimate and prove the test methodology and to determine the PID control parameters in the system, to link them to the flow parameters measured by temperature and pressure sensors. This study is fundamental for the stable operation of the ramjet engine.

The main results can be summarized as follows:

- The cold gas test system for a ramjet engine was built, assembled and tested;

- The analytical flow model in the air supply system was built and tested experimentally;

- The optimal characteristics of the PID control system were defined as: delay time at $5.04 \mathrm{~s}$, rise time at $6.25 \mathrm{~s}$, peak time at $7.45 \mathrm{~s}$, maximum overshoot in optimal flow test at $110 \%$, final pressure error at $0.23 \%$;

- The optimal PID operation parameters for the test ramjet engine were experimentally found, resulting in a reliable and repeatable airflow system operation, having low overshoot and pressure error.

Current results will allow in the future to perform the experimental study of a hot flow and to prepare the operation tests of the developed engine.

\section{AUTHOR'S CONTRIBUTIONS}

Conceptualization: Shynkarenko O; Methodology: Shynkarenko O and Freitas LC; Investigation: Shynkarenko O and Freitas LC; Writing - Original Draft: Freitas LC; Writing - Review and Editing: Shynkarenko O; Funding Acquisition: Shynkarenko O; Resources: Shynkarenko O; Supervision: Shynkarenko O.

\section{DATA AVAILABILITY STATEMENT}

All the datasets were generated during the current study.

\section{FUNDING}

Fundação de Apoio à Pesquisa do Distrito Federal - Grant No: 0193-000.199/2014.

http://dx.doi.org/10.13039/501100005668

\section{ACKNOWLEDGMENTS}

The authors are grateful to the Organization Committee of II Congresso Aeroespacial Brasileiro and to Marcelo Serrano Zanetti and the collaborators of the Chemical Propulsion Laboratory of the University of Brasilia for their assistance in current research work.

\section{REFERENCES}

[CPL] Chemical Propulsion Laboratory (2017) Design and development of a high-maneuverability supersonic missile with ramjet engine. Brasília: CPL; [accessed Aug 21 2020]. https://sites.google.com/aerospace.unb.br/cpl/projects/ramjet? 
[EAS] Emerson Automation Solutions (2017) Control valve handbook. Marshalltown: Fisher Controls International.

[MC] Measurement Computing (2012) Data acquisition handbook. Norton: Measurement Computing.

[NI] National Instruments (2015) NI 9265 Datasheet. Austin: National Instruments. [accessed Jan 23 2020]. http://www.ni.com/ pdf/manuals/374067a_02.pdf

[NI] National Instruments (2016a) NI cDAQ ${ }^{T M}-9171 / 9174 / 9178$ User Manual: NI CompactDAQ USB 2.0 Chassis. Austin: National Instruments. [accessed Jan 23 2020]. http://www.ni.com/pdf/manuals/372838e.pdf

[NI] National Instruments (2016b) NI 9208 Datasheet. Austin: National Instruments. [accessed Jan 23 2020]. http://www.ni.com/ pdf/manuals/375170b_02.pdf

[NI] National Instruments (2017) NI 9213 Datasheet. Austin: National Instruments. [accessed Jan 23 2020]. http://www.ni.com/ pdf/manuals/374916a_02.pdf

Anderson JD (2003) Modern compressible flow: with historical perspective. New York: McGraw-Hill.

Anderson JD (2016) Fundamentals of aerodynamics. New York: McGraw-Hill.

Araujo WS (2019) Metodologia de aquisição de dados experimentais em propulsão química (BSc thesis). Brasília: Universidade de Brasília. In Portuguese.

Danfoss (2016) Pressure transmitter for general purpose. Type MBS 1700 and MBS 1750. Nordborg: Danfoss; [accessed Oct 29 2020]. https://assets.danfoss.com/documents/DOC354735864202/DOC354735864202.pdf

Esirgen B (2014) Numerical and experimental investigation of direct connected ramjet test facility (Master thesis). Ankara: Middle East Technical University.

Frank SA (2018) Control theory tutorial: basic concepts illustrated by software examples. Cham: Springer. https://doi. org/10.1007/978-3-319-91707-8

Fry RS (2004) A century of ramjet propulsion technology evolution. J Propuls Power 20(1):27-58. https://doi.org/10.2514/1.9178

Hill PG, Peterson CR (1992) Mechanics and thermodynamics of propulsion. Boston: Addison-Wesley.

Inman DJ (2014) Engineering Vibration. New Jersey: Prentice Hall.

Mouritz AP (2012) Introduction to aerospace materials. Sawston: Woodhead Publishing. https://doi.org/10.2514/4.869198

Ogata K (2010) Modern control engineering. New Jersey: Prentice Hall.

Omega Engineering (2019) Super OMEGACLAD ${ }^{\circledR}$ XL thermocouple probes: A technological advance in temperature measurement. [accessed Jan 23 2020]. https://br.omega.com/omegaFiles/temperature/pdf/KMTXL_NMTXL.pdf

Sarisin MN (2005) Design of a connected pipe test facility for ramjet applications (Master thesis). Ankara: Middle East Technical University.

Sarisin MN, Tinaztepe HT, Ulas A, Albayrak K (2006) Conceptual design of a connected pipe test facility for ramjet applications. Paper presented 42nd AIAA/ASME/SAE/ASEE Joint Propulsion Conference \& Exhibit. AIAA; Sacramento, California, United States. https://doi.org/10.2514/6.2006-4446

Savvatimskiy AI (2005) Measurements of the melting point of graphite and the properties of liquid carbon (a review for 19632003). Carbon 43(6):1115-1142. https://doi.org/10.1016/j.carbon.2004.12.027 
Shynkarenko O, Azevedo, VA, Veras CAG, Alves IPM (2019a) Experimental investigation of hydrocarbon based fuels in solid fuel ramjet. Paper presented 70th International Astronautical Congress. AIAA; Washington, District of Columbia, United States.

Shynkarenko O, Simone D, Lee J, Andrianov A, Bertoldi AEM, Souza KM (2019b) Flame initiation inside the gas torch ignition system for a hybrid rocket motor. Paper presented 70th International Astronautical Congress. AIAA; Washington, District of Columbia, United States.

Souza NS (2014) Síntese e estudo das propriedades físicas de grafite ferromagnético fluido nanoestruturado (PhD thesis). São Carlos: Universidade Federal de São Carlos. In Portuguese.

Sutton GP, Biblarz O (2010) Rocket propulsion elements. Hoboken: John Wiley Sons.

White FM (2011) Fluid Mechanics. New York: McGraw-Hill. 